\title{
A WIND TURBINE SIMULATOR USING ANN CONTROLLED DC DRIVE
}

\author{
M. E. Abdel- Karim \\ Dept. of Elect. Engg., Faculty of Engg. \\ Minufiya University, Shebin El-Kom, EGYPT
}

\begin{abstract}
This paper presents a new simulator using a dc motor drive to simulate the characteristics of a vertical-axis wind turbine in steady-state operation. The drive system consists of a separately excited dc motor fed via a thyristor converter. This drive is controlled by its Artificial Neural Network (ANN) inverse model using the wind turbine model as a reference. The controller is implemented by a LabView software program which provides a great flexibility and gives the possibility to simulate any wind turbine characteristics. The proposed simulator is tested for both dynamic and steady state modes at different wind velocities and loads. It is shown that the steady-state characteristics of the proposed simulator follow, satisfactorily, those of the actual wind turbine.
\end{abstract}

\section{List of symbols}

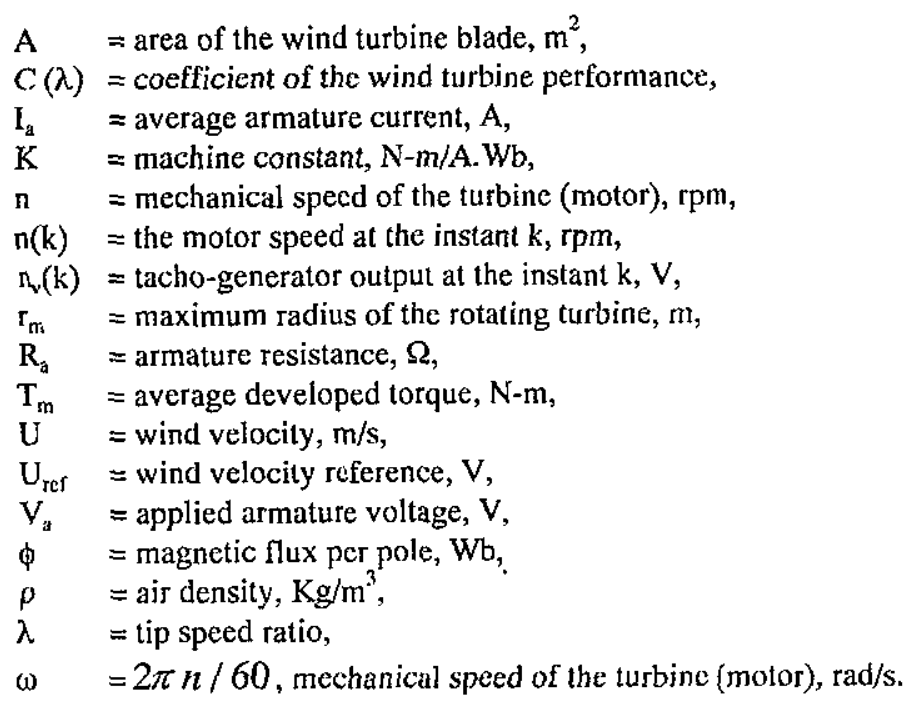

\section{Introduction}

Recently, the interest in wind energy has been increased, where it is considered one of the most important and promising forms of renewable energy sources[1]. The wind energy conversion systems (WECS) have been increased around the world either as part of public grid or as isolated power generating units. For instance, in France, a project (EOLE2005) aims at increasing the installed wind energy capacity to several hundreds of MW by the year 2005[2].

Manuscript received from Dr.M.E. Abdel karim on : 21/3/2000

Accepted on : 8/4/2000

Engineering Research Bulletin, Vol 23,No 3, 2000 Minufiya University, Faculty of Engineering, Shebien El-Kom, Egypt, ISSN 1110-1180 
The rapid progress which has been achieved in the development of variable and economic WECS has made it possible to gain experience in designing, manufacturing and testing different types of WECS[3]. To achieve those

experimental tests, models for the wind turbine have to be built. On the other hand, the test procedures have to wait for a natural wind with appropriate velocity or use an artificial wind which may need a long time and high cost. To avoid these problems, a wind turbine simulator is necessary to design and test different types of WECS[4,5]. Several wind turbine simulators have been developed, but their performance and flexibility need to be improved[3-5]. A manual control of the armature and/or field voltage of the dc motor has been introduced to simulate the vertical axis wind turbine[4], but the armature circuit resistance needs to be continuously changed to change the operating point on the torque-speed characteristics. Another method for wind turbine simulation based on wind turbine characteristics has been presented[3], but it is expensive and relatively complex. It uses a micro-controller connected to the serial port of a personal computer and communicates with it through a transmitter. An alternative method based on control of the armature voltage of a separately excited dc motor, such that the motor tracks the wind turbine characteristics has also been reported[5]. However, that method was implemented using operational amplifier circuits whose parameters were adjusted for a certain operating point of a piece-wise linear model of the non-linear system. Those circuits have the tendency to drift with age and temperature causing degradation of the system performance.

In this paper, a new simulator for simulating a vertical axis wind turbine in various modes of operation using a separately excited dc motor fed from a thyristor converter is proposed. The proposed simulator is controlled by an ANN inverse model of $\mathrm{dc}$ motor drive (converter/motor/load) using the wind turbine model as a reference. The ANN's role is to model the non-linearties and parameter uncertainties of the motor drive[8-10]. This model allows mapping at high precision with the wind turbine reference model. This controller is implemented using a personal computer with LabView software through a data acquisition card Lab-pc1200. The proposed simulator is tested for both dynamic and steady state modes at different wind velocities and loads for $17 \mathrm{~m}$ Darrieus turbine. This simulator is also tested to simulate other wind turbines by modifying parameters of the wind turbine reference model

\section{Vertical Axis Wind Turbine}

There are two basic types of wind turbines that are commonly used in different regions of the world[4-7], i.e of horizontal axis or of vertical axis. The present work considers a vertical axis wind turbine such as that shown in Fig. (1). It has several attractive features[6,7]. For instance, the turbine rotates about a vertical axis, and hence it does not need to be oriented into the wind. Also, the blades take the shape of a jumping rope experiencing high centrifugal force. The blades operate in almost pure tension, and so a relatively light and inexpensive blades are sufficient. In addition, the power train, generator and controls are all located near ground level. Hence they are easy to construct and maintain. The 
efficiency of this type is nearly as good as that of the horizontal axis propeller turbine. So, the vertical axis wind turbine holds considerable promise as a costeffective turbine.

The average output torque $\mathrm{T}_{\mathrm{T}}$ of the wind turbine is given by[3-7]:

$$
T_{T}=0.5 \rho r_{m} A C(\lambda) U^{2}
$$

The coefficient of performance $C(\lambda)$ is a non-linear function of the tip speed ratio:

$$
\lambda=\frac{\omega r_{m}}{U}
$$

The variation of $\mathrm{C}$ with $\lambda$ for one of those turbines called Darrieus wind turbine is shown in Fig.(2). The torquespeed characteristics of such turbine, based on eqns. (1) and (2), are shown in Fig.(3)[4,7].

\section{Control Algorithm}

The objective of the control algorithm is to design a controller for the dc drive such

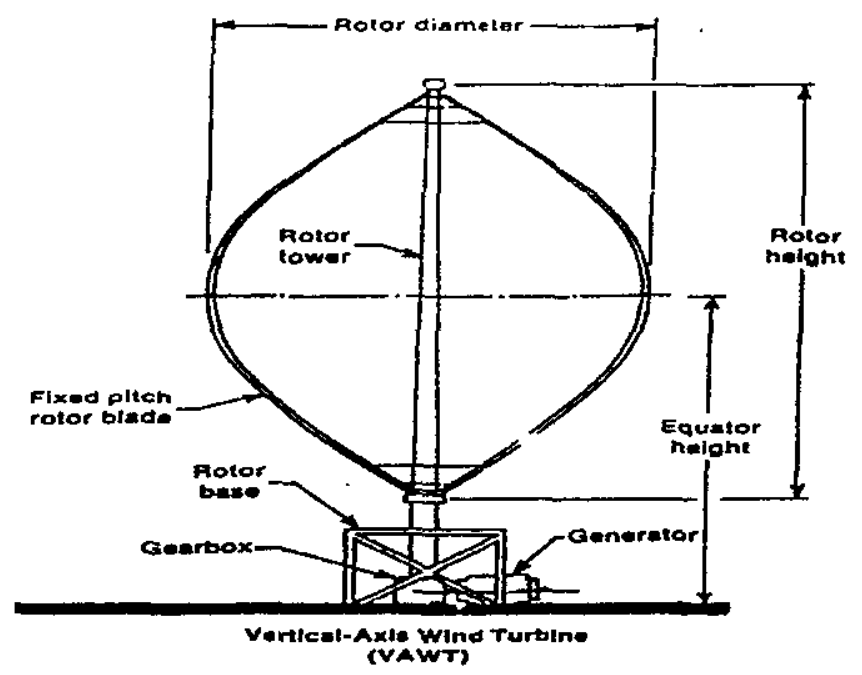

Fig. 1: Vertical-axis wind turbine. that the torque-speed characteristics of the real wind turbine can be tracked. The dc motor can be represented by the following two steady state equations $[4,5]$ :

$$
\begin{aligned}
& T_{m}=K \phi I_{a} \\
& V_{a}=K \phi \omega+R_{a} I_{a}
\end{aligned}
$$

If the dc motor is separately excited, the flux $\phi$ becomes a constant, and from eqn.(3), it is seen that the torque is directly proportional to the armature current $I_{a}$. Since it is desired to simulate the output torque-speed characteristics of the wind turbine by that of the dc motor, eqns (1) and (3) give:

$$
I_{r e f}=K_{T} C(\lambda) U^{2}
$$

By controlling the applied armature voltage $V_{a}$, the armature current $I_{a}$ can be forced to track the reference current $I_{\text {rel }}$, given by eqn.(4). From $C(\lambda)$ given by Fig.(2) and eqn.(2), $\mathrm{I}_{\mathrm{ref}}$ is a function of the motor speed $\mathrm{n}$ with the wind velocity $\mathrm{U}$ as a parameter. So, it is possible to simulate the torque-speed characteristics of the vertical axis wind turbine such as shown in Fig.(3)[4,7].

\section{The Proposed Wind Turbine Simulator}

The characteristics of the vertical axis wind turbine is simulated using a separately excited dc motor supplied by a single phase half-controlled bridge. The system components are shown in Fig. (4). The "PC controller" of Fig. (4) is as shown in Fig.(5). The de motor is loaded using an electric brake, and so the 
brake arm is used to impose different loading conditions to the simulator. The components $T_{1}, T_{2}$, and $T_{3}$ are dedicated to the measurements and signal conditioning.

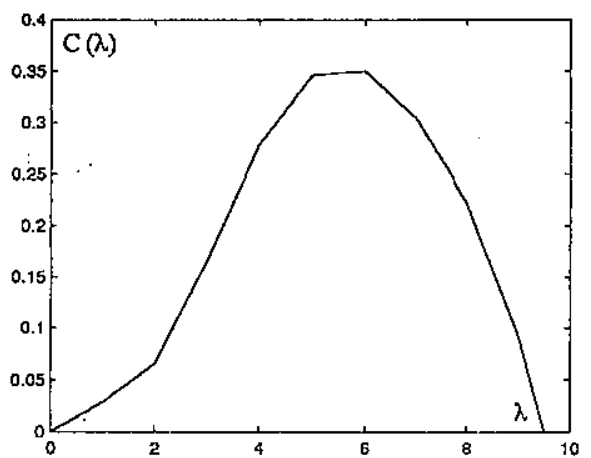

Fig. 2: $C(\lambda)$ versus tip-speed ratio $\lambda$ for $17 \mathrm{~m}$ Darrieus turbine.

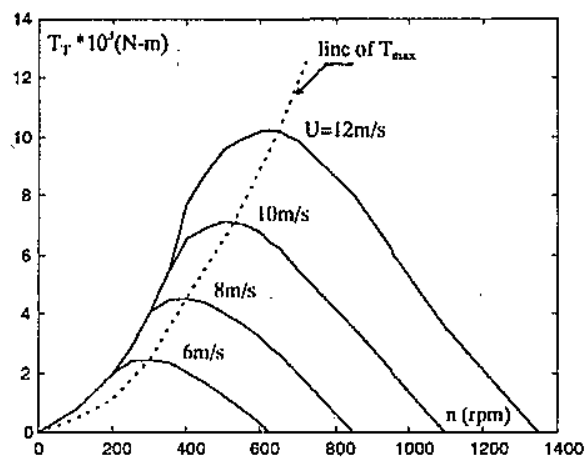

Fig.3: Torque-speed curves of $17 \mathrm{~m}$ Darrieus at different $U$.

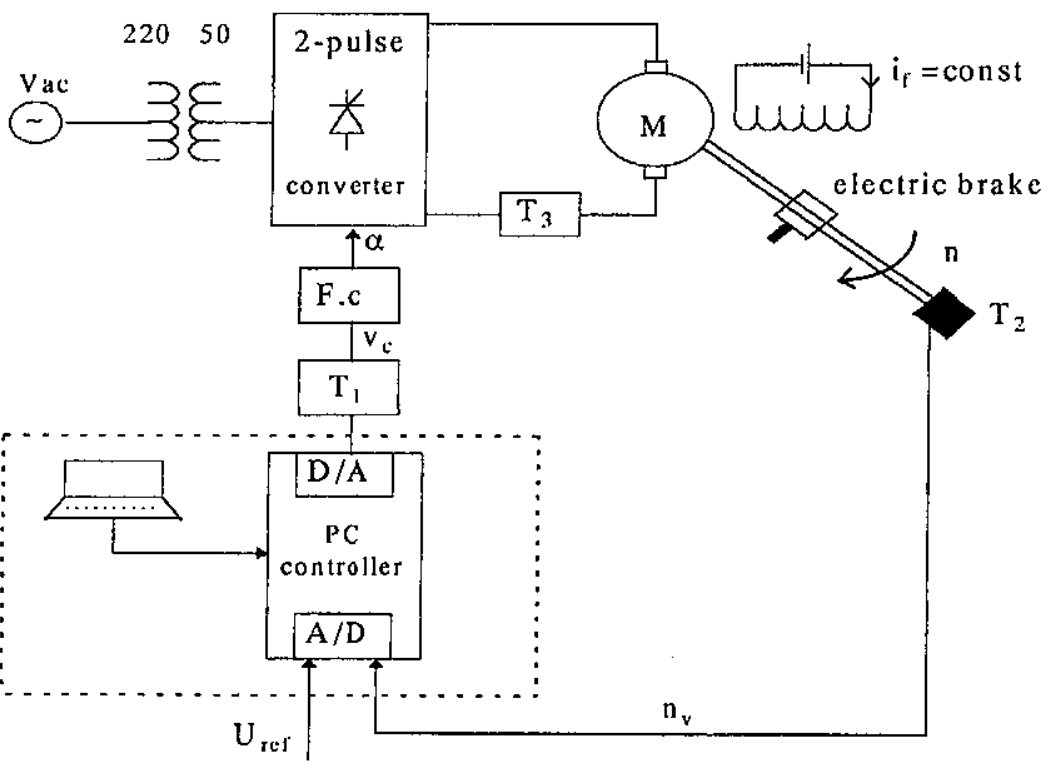

Fig.4: Schematic diggram of the proposed wind turbine simulator.

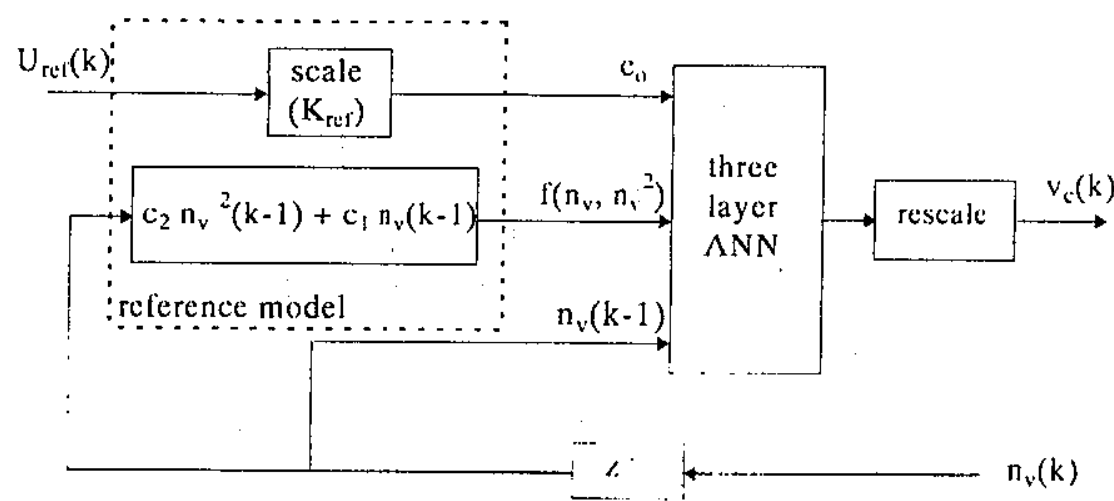

Fig 5: The controller block diagram for the proposed simulator. 
As shown in Fig.(5), the controller uses ANN inverse model of the dc motor drive in conjunction with the wind turbine model as a reference. The ANN inverse model is used as feedforward rules to calculate the appropriate control signal for the converter in order to manipulate its terminal voltage in such a manner as to make the motor torque-speed characteristics follow that of the wind turbine.

\section{4-1. Wind turbine reference model}

The first step for the controller design is to select a suitable reference model for the motor current $I_{a}$ to follow the wind turbine trajectory, $I_{\text {ref }}$, of eqn.(4). This equation represents the actual torque-speed characteristics of the Darrieus wind turbine as shown in Fig.(3). The actual characteristics must be scaled to be appropriate for the considered motor characteristics. Knowing the ratings of the motor simulator $(50 \mathrm{~V}, 3 \mathrm{~A}, 2000 \mathrm{rpm})$, the motor full load torque is calculated. Referring to Fig.(3), the turbine peak torque is equated by the calculated full load torque of the motor. Then, the torque axis is then scaled accordingly, whereas the values of $\mathrm{n}$ and $\mathrm{U}$ remains as shown in Fig.(6).

To obtain the wind turbine reference model, eqn. (4) is fitted using the scaled torque-speed characteristics, shown in Fig.(6), resulting the following equation:

$$
\begin{aligned}
& I_{r e f}(k)=c_{2} n^{2}(k)+c_{1} n(k)+c_{0} \\
& I_{r e f}(k)=f\left(n, n^{2}\right)+c_{0}
\end{aligned}
$$

This reference model is used to estimate the reference armature current. Accordingly, the motor torque follows that of the real wind turbine system. As shown in Fig.(6), the right part of the curve is fitted where the system behaviour is stable. The first and second terms on the right side of eqn.(5), $f\left(n, n^{2}\right)$, are determined by the motor speed and could be used to follow the characteristic of the simulated wind turbine at each wind velocity. This is achieved by varying the equation parameters $c_{2}$ and $c_{1}$. The third term, $c_{0}$, allows for changing the no-load motor speed, which represents the wind velocity $U$. This term is adjusted by the wind velocity reference, $U_{\text {ref }}$ and the scaled coefficient $K_{\text {rcf }}$, to give the desired wind velocity. The components of the reference model are as shown in Fig. (5).

For a wind velocity and turbine speed of $11 \mathrm{~m} / \mathrm{s}$ and $1100 \mathrm{rpm}$, respectively, the coefficients of eqn.(5) are:

$$
c_{2}=-1.66 \times 10^{-6} \quad c_{1}=8.68 \times 10^{-4} \text {, and } \quad c_{0}=0.9449 \text {. }
$$

Technically, the data acquisition card DAQ can not handle signals larger than 5 volt. The gain of the tacho-generator, $T_{3}$, is $2 \mathrm{v} / 1000 \mathrm{rpm}$, and so, the possible maximum motor speed is $2500 \mathrm{rpm}$. Consequently the previous coefficients (at $U=11 \mathrm{~m} / \mathrm{s}$, and $\mathrm{n}=1100 \mathrm{rmm}$ ) should be scaled before being used in the reference model program and eqn.(5) becomes:

$$
I_{r e f}(k)=-0.266 n_{v}^{2}(k)+0.347 n_{v}(k)+0.944
$$


The LabView software through DAQ lab-pc1200 receives all the information in order to realise the reference model of Fig. (5). Once it is informed about the wind velocity $U$, according to the wind velocity reference $U_{\text {ref }}$ and the sampled dc motor speed $n_{v}$, it calculates the reference current $I_{\text {ref }}$ for ANN inverse model as shown in Fig. (5).

\section{4-2. ANN inverse model and structure}

In general, the dc drive systems

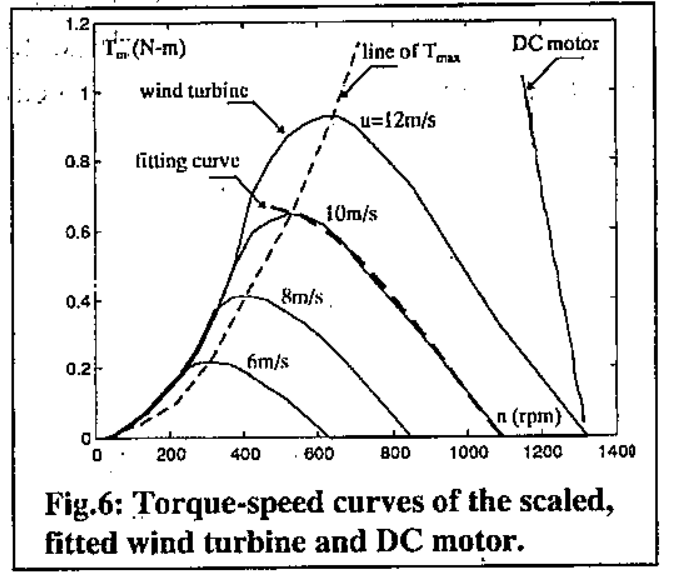
are non-linear and have some parameter uncertainties such as the magnetic field and the armature reaction. Designing a controller to track their dynamic behaviour is difficult. A simplified linear model may not be accurate and a controller design based on it may lead to sub-optimal performance and in some cases it may cause total instability of the drive system. The ability of ANN to learn a large class of non-linear functions is well known[8,9]. The ANN's role is to model the non-linearties and parameter uncertainties of the motor drive. This model allows mapping, at high precision, with the output of the wind turbine reference model.

The converter/motor/load model can be represented by a second order non-linear differential equation. This equation can be transformed to second order nonlinear difference equation as follows[8-10]:

$$
n(k)=f\left(n(k-1), i_{a}(k-1), v_{c}(k)\right)
$$

The above equation is used to build ANN forward model of the de drive. The input to the ANN forward model must be $n(k-1), i_{a}(k-1)$ and $v_{c}(k)$ while the output, after training, must be equal to $n(k)$. The converter control voltage $v_{c}(k)$ can be obtained by modifying the ANN forward model to give the ANN inverse model as follows[10]:

$$
v_{c}(k)=f\left(n(k), n(k-1), i_{a}(k-1)\right)
$$

The aim of the ANN inverse model is to build a control system which allows tracking of motor reference current trajectories given by eqn.(6). In this case, $\mathrm{n}(\mathrm{k}), \mathrm{n}(\mathrm{k}-1)$, and $\mathrm{i}_{\mathrm{a}}(\mathrm{k}-1)$ are the inputs to the ANN inverse model and the output is the control voltage $v_{c}(k)$, as shown in Fig (5).

Using a LabView software and DAQ lab-pc1200, a set of training data $n_{v}(k)$, $\mathrm{n}_{\mathrm{v}}(\mathrm{k}-1), \mathrm{i}_{\mathrm{a}}(\mathrm{k}-1)$, and $\mathrm{v}_{\mathrm{c}}(\mathrm{k})$ is created by applying ramp-up control voltage $\mathrm{v}_{\mathrm{c}}(\mathrm{k})$ to the converter firing circuit, and meanwhile another ramp-up of motor load with different rate is applied. The training data is generated to cover the possible operating parameters (such as speed, current, and reference control voltage), as shown in Fig.(7). The error between the actual control voltage $v_{c}$ and the computed $v_{c}$ (ANN) is used to train the ANN using the back-propagation algorithm. Five neurons in the hidden layer with tansigmoid activation function 
and a single neuron in the output layer also with tansigmoid activation function are used. The learning rate $\eta$ is adjusted by trial and error to a value equal 0.0002 . Figure $(8)$ shows the trained neural network output, $v_{c}(A N N)$, and the actual control voltage, $\mathrm{v}_{\mathfrak{c}}$. It is clear that the ANN is trained well and this figure indicates that the ANN fits well with the non-linear inverse model of converter/motor/load.

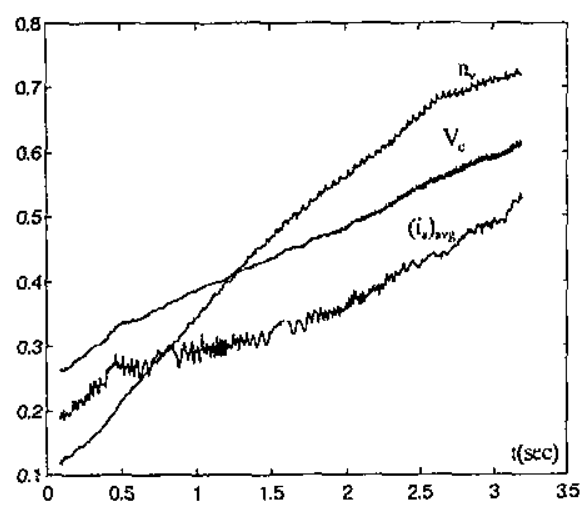

Fig. 7: The training data curves of $\mathbf{n}_{v}$, $\left(i_{a}\right)_{2 v g}$ and $v_{c}$ for $A N N$.

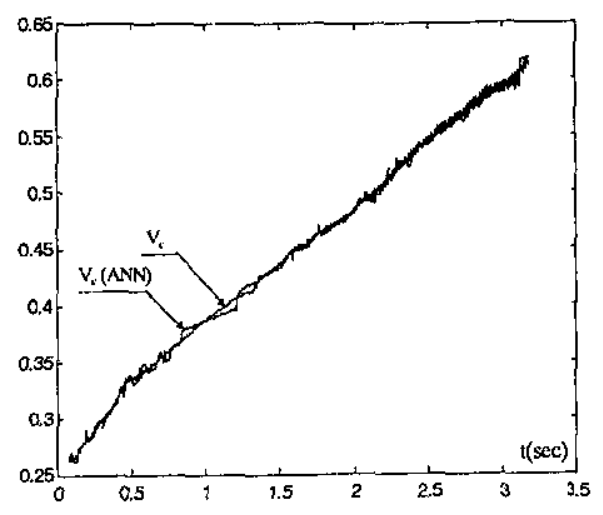

Fig. 8: Output of the ANN inverse model of trained the de drive with ramp up of $v_{c}$.

\section{4-3. Simulator measuring circuits}

The components $T_{1}, T_{2}$, and $T_{3}$, shown in Fig.(4), are dedicated for the measurement and signal conditioning. $T_{1}$ is a Hall-effect voltage sensor (LV25NP from LEM) to modulate, amplify, and isolate the control voltage signal from the D/A port of DAQ lab-pc1200 to the analog firing circuit (F.C). $T_{2}$ is a tachogenerator with gain $2 \mathrm{v} / 1000 \mathrm{rpm}$ and its output voltage is directly connected to the DAQ Lab-pc1200. $T_{3}$ is a Hall-effect current sensor (LA25-NP from LEM) for measuring as well as adapting the armature current to the $A / D$ port of Labpc1200 for calculating the torque-speed characteristics using the LabView software.

\section{Experimental Results}

The proposed wind turbine simulator was tested at different operating conditions. Samples of the experimental results are given below.

ln Fig.(9a), the steady-state torque-speed characteristics of the actual wind turbine were compared with the experimental ones of the proposed simulator, considering the wind velocity as a parameter. It is clear that, the steady state characteristics of the real wind turbine are reproduced well by the proposed simulator for different wind velocities. Also, the line of maximum torque at different wind velocities is monolithically increased and is closely similar to the maximum torque line of the wind turbine characteristics shown in Fig.(6). However, only the stable parts of the torque-speed characteristics are considered. The corresponding armature voltage variations are recorded as shown in Fig.(9b). 
The proposed simulator can be modified to simulate other wind turbines, by modifying the parameters $\left(c_{2}, c_{1}\right.$, and $\left.c_{0}\right)$ of eqn.(6) as shown in the Table. Figure (10a) shows the experimental steady-state torque-speed characteristics of the proposed simulator for different wind turbines (WT). The corresponding curves of armature voltage are shown in Fig. (10b).

\begin{tabular}{|c|c|c|c|}
\hline $\begin{array}{c}\text { wind } \\
\text { turbine (WT) }\end{array}$ & $c_{2}$ & $c_{1}$ & $c_{0}$ \\
\hline $\mathrm{WT}_{1}$ & -0.425 & 0.56 & 1.5 \\
\hline $\mathrm{WT}_{2}$ & -0.37 & 0.48 & 1.32 \\
\hline $\mathrm{WT}_{3}$ & -0.32 & 0.42 & 1.13 \\
\hline $\mathrm{WT}_{4}$ & -0.26 & 0.34 & 0.94 \\
\hline $\mathrm{WT}_{5}$ & -0.21 & 0.28 & 0.755 \\
\hline $\mathrm{WT}_{6}$ & -0.13 & 0.17 & .0 .47 \\
\hline
\end{tabular}

Figures (11\&12) show the dynamic response of the proposed simulator for the sudden changes of reference voltage (wind velocity) and brake arm (turbinc torque). Figure (11) corresponds to an increase of the reference voltage from 5.5 to 6 volt, so that the motor speed increased from 650 to $900 \mathrm{rpm}$ and the motor torque was increased from 0.35 to $0.4 \mathrm{~N}$-m as expected from Fig.(9a). Figure(12) corresponds to an increase the brake arm with $U_{\text {ref }}$ is $6.2 \mathrm{volt}$, so that the motor speed decreased from 900 to $800 \mathrm{rpm}$ and meanwhile the motor torque was increased from 0.4 to $0.45 \mathrm{~N}-\mathrm{m}$. However, the proposed simulator can track selected torque-speed characteristics in the steady state, but during transition from one to another it approaches the steady state much faster than the actual turbine. In order to achieve accurate simulation during transition, parameters of the reference model may be modified, but this results in deviations in steady-state characteristic. Further studies are still required to achieve more accurate results in dynamic cases while keeping acceptable accuracy in steady-state.
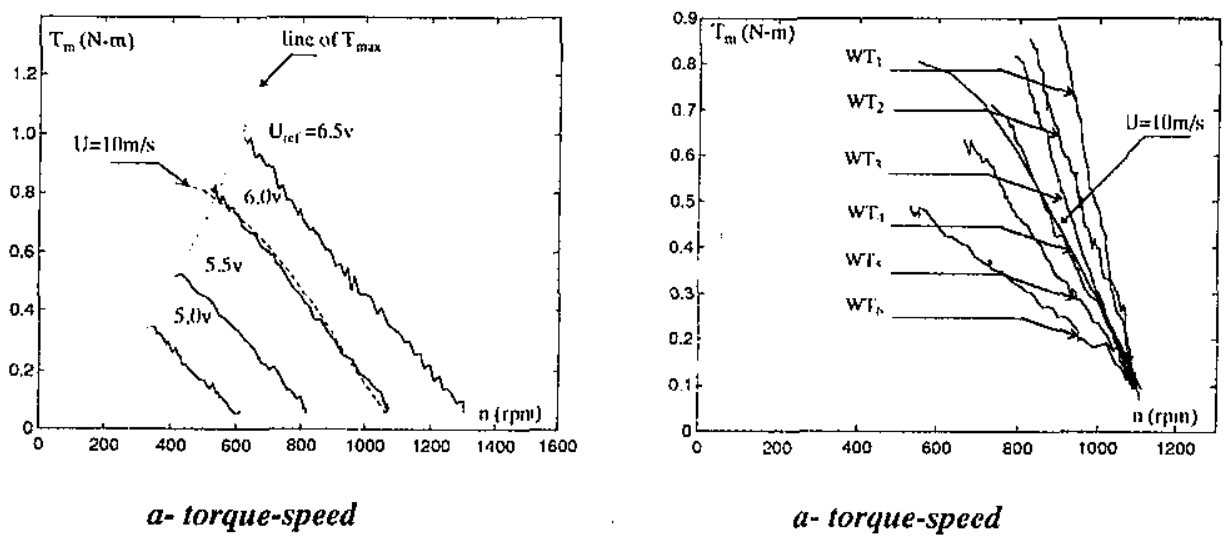


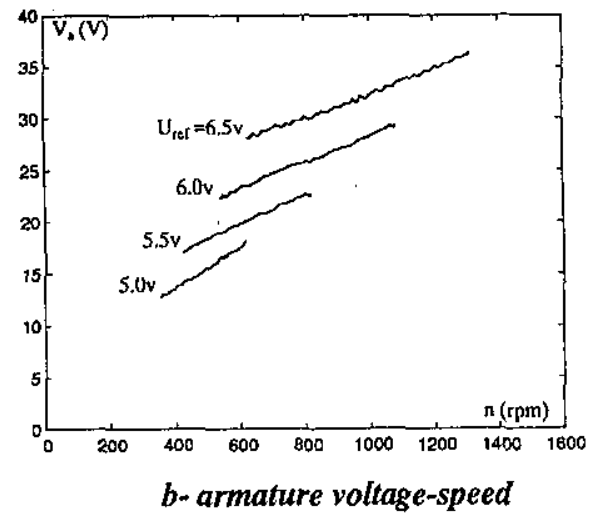

Fig. 9: Experimental curves of simulator at different $\mathrm{U}_{\text {ref }}$

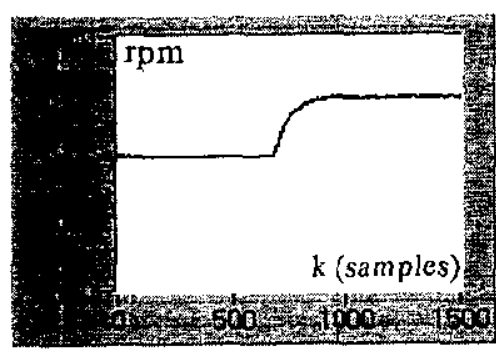

a- motor speed

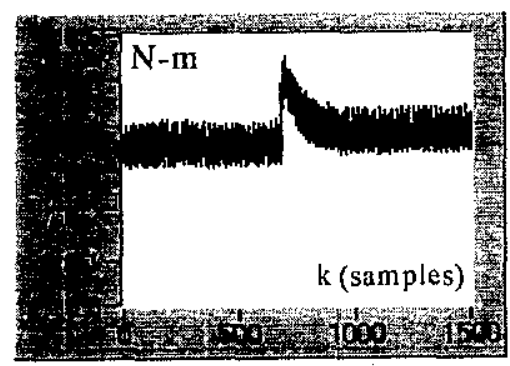

b- motor torque

Fig. 11: Time response of the simulator during a step change of $\mathrm{U}_{\mathrm{rer}}$.

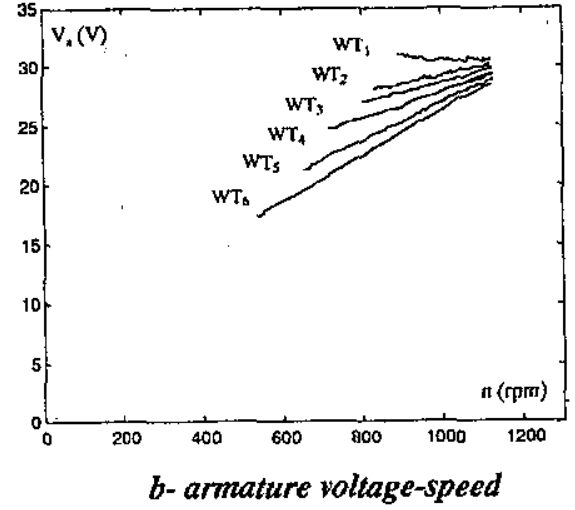

Fig.10: Experimental curves of the imulator at $U=10 \mathrm{~m} / \mathrm{s}$ and different $c_{2}, c_{1}$, and $c_{0}$.

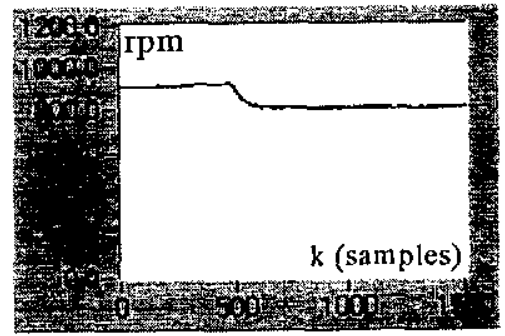

a- motor speed

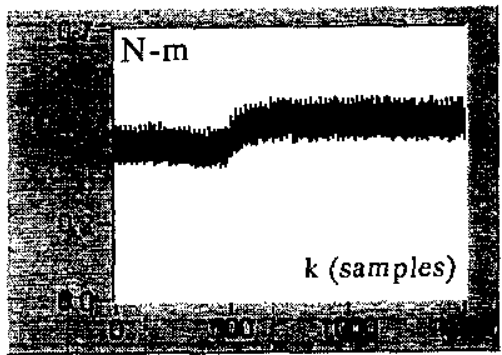

b- motor torque

Fig.12: Time response of the simulator during a step change of load.

\section{Conclusions}

(time $=\mathrm{k} \mathrm{T}$, where the sampling interval $\mathrm{T}=1 / 150$ )

In this work, a small-scale wind turbine simulator has been proposed and examined. The control of this laboratory simulator has been based on ANN inverse model of a dc drive, in conjunction with the wind turbine model as a reference and a LabView software for implementation of the control algorithm. The flexibility and fast response of the dc drive employed provided accurate simulation of the torque-speed characteristics of the vertical axis wind turbine. The proposed simulator has been tested for both dynamic and steady state modes at different wind velocities and loads. It has been shown that the steady-state characteristics of the proposed simulator follow those of the actual wind turbine, 
satisfactorily. Nevertheless, the proposed simulator allows an easy adaptation to simulate any WECS characteristics.

\section{Acknowledgment}

The author appreciates the experimental facilities provided by faculty of Engg. Shebin El-kom. He would also like to thank Prof. Dr F. E. Abdel- Kader for the helpful discussions, and Prof. Dr. A. S. Abdel-karim for reviewing the paper.

\section{References}

1I V. C. Tsimplostephanakis, A. N. Safacas, "Dynamic analysis and control of wind energy conversion system using an asynchronous generator connecting at a weak grid", $3^{\text {rd }}$ International symposium on advanced Electromechanical Motion systems, pp. 897-902, Patras, 1999.

2] B.Brobyns, and M. Esselin, "Power control of an inverter-transformer association in a wind generator", $3^{\text {rd }}$ ibid, pp. 891-895.

3] I. Rogakos, E. Tatakis, E. Tsimplostephanakis, A. Safacas, "A flexible wind turbine simulator using micro-controller", $3^{\text {rd }}$ ibid, pp. 879-883.

4] S. A. Kalilah, H. M. Diab, and F. E. Abdel- kader, "New model of wind turbine using an clectric motor", Proc. $2^{\text {nd }}$ International Conference on Engg. Research, vol. I, pp. 23- 33, Port-Said, Egypt, Dec. 1995.

5] R. M. Hilloowala, and A. M. Sharaf, "A utility interactive wind energy conversion scheme with an asynchronous de link using a supplementary control loop", IEEE Transactions on Energy Conversions, vol. 9, No.3, pp. 558- 563, September 1994.

6] E. Peltola, "A comparison of constant and variable-speed drives for wind turbines", Electromechanical Research Symposium of Helsinki University of Technology, Otaniemi, August 21\&22, 1987.

7] Gary L. Johnson, "Wind energy systems", Prentice-Hall, Inc., Englewood Cliffs, and New Jersey, 1985. (Book)

8] S. Weerasooriya, and M. A. El- Sharkawi, "Identification and control of de motor using back-propagation neural networks "IEEE trans. on Energy Conversion, Vol. 6, No. 4, March 1991

9] S. Weerasooriya, and M. A. El- Sharkawi, "Laboratory implementation of a neural network trajectory controller for a dc motor ",IEEE trans. on Energy Conversion, Vol. 8, No. 1, March 1993.

10] F. M. El-khouly, et al., "Artificial intelligent speed control strategies for permanent magnet dc motor drives", IEEE Industry Application Society Annual Meeting, 2-7 October 1994, Denver, Colorado, USA. 


\title{
محاكى للثربينة الهو/ئية بإستخدام آلمة تسيير تبار مستصر محكومة بشبكة عصبية إصطناعية
}

\author{
د/مصطفى اللسيد عبد الكريم \\ كلية الهندسة بشّبين الكوم - جامعة المنوفية
}

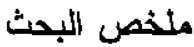

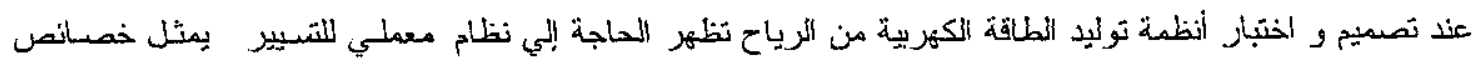

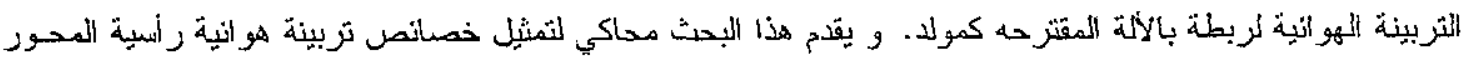

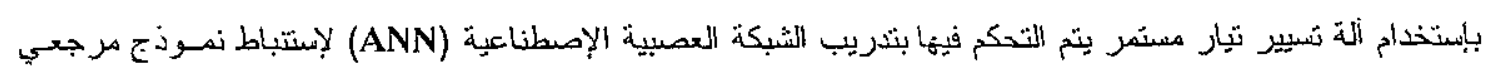

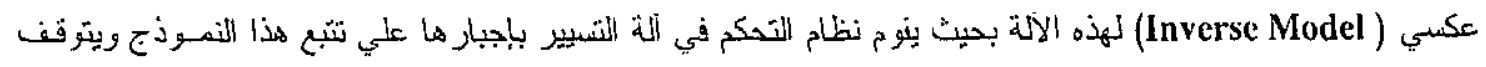

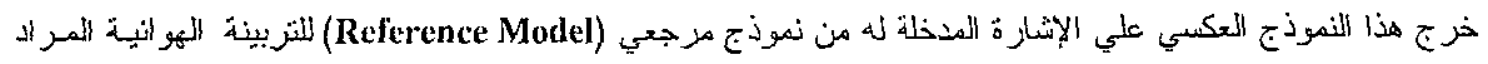
تمنيل خصائصها.

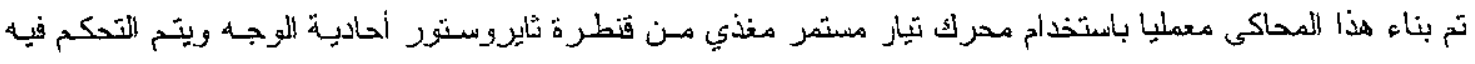

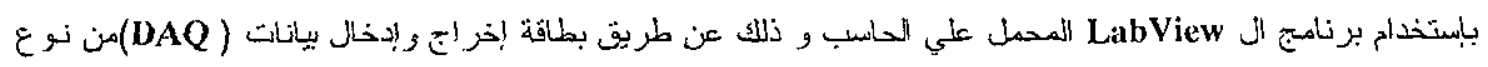

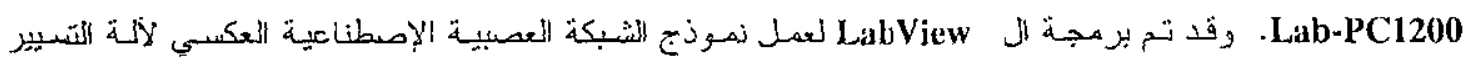

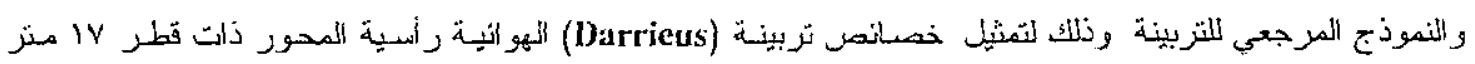

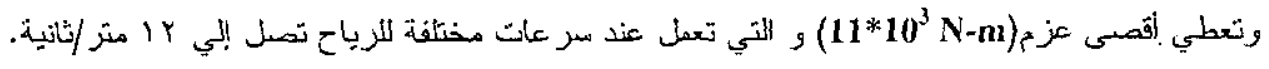
تم اختبار هذا المحاكي معمليا عند سر عات مختلفة للريباح و عند حالات مختلفة دن التحفيل للتربينة. وقد أظهرت

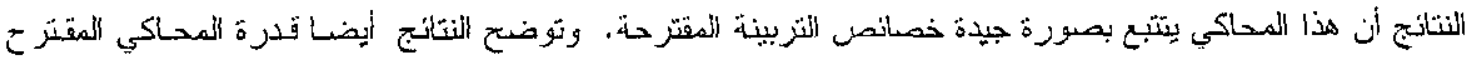

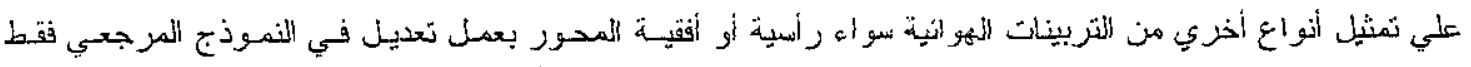
يناسب التزبينة المطلوب تمثيل خصانصيها. 